Revisión

\title{
Patología Molecular de los sarcomas
}

E. de Álava

\section{Resumen}

Los sarcomas de hueso y tejidos blandos son un grupo poco frecuente de tumores. Su prevalencia es inferior a 1 caso por 10000 habitantes, lo que los convierte en una enfermedad rara. Algunos de estos tumores, como el sarcoma sinovial, el tumor de Ewing o el osteosarcoma, son más habituales en los adolescentes o en los adultos jóvenes, mientras que existen neoplasias como el leiomiosarcoma o el liposarcoma, más frecuentes en pacientes de edad superior a los 55 años. Desde el punto de vista histológico existen más de cien tipos diferentes de sarcomas. Por esta razón es difícil encontrar grandes ensayos clínicos de pacientes con tipos concretos de sarcomas. Desde el punto de vista molecular estas neoplasias se agrupan en dos tipos principales: (a) sarcomas con alteraciones genéticas específicas y cariotipos relativamente simples, con translocaciones que originan fusiones génicas (p.ej EWS-FLI1 en el tumor de Ewing), o bien mutaciones puntuales específicas (p.ej. de c-kit en el GIST), y (b) sarcomas con alteraciones génicas inespecíficas y cariotipos muy complejos, con ganancias y pérdidas muy numerosas. En esta revisión se describen los diversos tipos de alteraciones moleculares y su utilidad en el campo clínico.

\section{Palabras clave:}

Patología. Biología molecular. Patología molecular. Sarcoma. Hueso. Tejidos blancos. Traslocación. Mutación.

Oncología, 2005; 28 (9):426-442 


\section{Summary}

Bone and soft tissue sarcomas are rare tumors. Their prevalence is below 1 per 10,000 inhabitants. Some of them are more prevalent in the adolescent-young adult age group, while others usually arise in the late adulthood. From the histopathological point of view there are over 100 sarcoma types. Therefore it is almost impossible to find a clinical trial on a specific sarcoma type.

From the molecular standpoint these neoplasms usually fall into two groups: a) sarcomas with specific molecular alterations and relatively simple karyotypes, with translocations giving rise to gene fusions (as EWS-FLI1 in Ewing tumor) or point mutations (as GIST), and b) sarcomas with nonspecific molecular features and complex karyotypes. We will review the different types of mutations in sarcomas as well as their clinical value.

Key words: Pathology. Molecular pathology. Sarcoma. Bone. Soft tissue. Translocation. Mutation.

\section{Introducción}

Los sarcomas de hueso y tejidos blandos son un grupo heterogéneo y poco frecuente de tumores. Suponen menos del 5\% de las neoplasias de los pacientes adultos, y aproximadamente un $10 \%$ de los tumores infantiles. A pesar de esta diferencia en proporción, en números absolutos son tumores más frecuentes en la edad adulta ${ }^{1}$. Algunos de estos tumores, como el sarcoma sinovial, el tumor de Ewing o el osteosarcoma, son más habituales en los adolescentes o en los adultos jóvenes, mientras que existen neoplasias como el leiomiosarcoma o el liposarcoma, más frecuentes en pacientes de edad superior a los 55 años. Desde el punto de vista histológico existen más de cien tipos diferentes de sarcomas; aunque algunos son de histogénesis incierta, como el sarcoma sinovial, otros muestran rasgos similares a los de ciertos tipos celulares normales del tejido mesenquimal, como el cartílago, el tejido adiposo, o el músculo, desde los que aparentemente surgen. Por esta razón es difícil encontrar ensayos clínicos grandes de pacientes con tipos concretos de sarcomas. Sabemos muy poco de la causa de los sarcomas. Conocemos algunos factores de riesgo ambientales asociados a algunos tipos concretos de sarcoma, como el cloruro de vinilo y el angiosarcoma hepático, o la radiación ionizante, que se asocia a varios tipos de sarcomas; existen cuatro síndromes de cáncer familiar asociados a sarcomas, pero en su gran mayoría la patogenia se basa en la presencia de mutaciones adquiridas.

Mientras no se dispuso de un tratamiento altamente efectivo para los sarcomas, el diagnóstico de los mismos no necesitó ser particularmente preciso: se trataba en cualquier caso de tumores muchas veces letales. Hoy día, el diagnóstico anatomopatológico de los sarcomas sigue siendo un auténtico reto, debido a su rareza y a su frecuente indiferenciación, pero también al hecho de que existen tratamientos eficaces y específicos para muchos de ellos, que han dejado por tanto de ser neoplasias letales.

El objeto de esta revisión es el de mostrar que se puede realizar el diagnóstico de estas neoplasias integrando las técnicas convencionales y las más avanzadas, siempre en un contexto anatomoclínico. Hacemos énfasis en este último aspecto porque, especialmente en el caso de la Anatomía Patológica de los sarcomas pediátricos, ambos tipos de técnicas, las más convencionales y las 'especiales', son insustituibles, y deben ser interpretadas de manera integrada entre sí, junto con los datos de anamnesis, exploración e imagen. Este hecho sigue requiriendo la tradicional colaboración del patólogo con el experto en diagnóstico por imagen, el oncólogo, el cirujano, y el biólogo (o patólogo) molecular para el diagnóstico y manejo correctos del sarcoma. 


\section{E. de Álava}

Para realizar la integración a la que nos referimos es fundamental la toma de una muestra adecuada para realizar un diagnóstico anatomopatológico, y que además permita la preservación de tejido y células en formatos y temperaturas adecuadas para la realización de estudios complementarios, como los que se refieren más adelante, que se basan en el análisis de ácidos nucleicos y proteínas. En concreto, lo adecuado sería que todos los tejidos se remitieran desde el quirófano en fresco, y que a la llegada al servicio de Anatomía Patológica, se fije material en formol, se puedan congelar fragmentos de tejido, se realicen improntas titulares y, en el mejor de los casos, se puedan realizar suspensiones celulares y cultivos celulares. Es importante que la toma para estos procedimientos especiales se realice por parte del patólogo, por un lado para asegurar la integridad de los márgenes quirúrgicos, y por otro lado para garantizar que el tejido congelado corresponde realmente al material que se desea preservar. Es muy importante que la toma de este material se realice una vez asegurado el diagnóstico anatomopatológico de la neoplasia en cuestión, que es la finalidad principal para la que el paciente da su consentimiento informado. A partir del material almacenado se pueden establecer bancos de tumores cooperativos para fomentar la investigación y el diagnóstico molecular de los tumores. Se pueden encontrar protocolos detallados y recomendable en la web de la Red Temática de Investigación de Centros de Cáncer o en la de la Red Temática de Investigación de Tumores Pediátricos sólidos ${ }^{2}$.

\section{Alteraciones moleculares}

Adquiridas-somáticas. Se detectan 5 grandes tipos de mutaciones adquiridas en los sarcomas. Deleción: Supone cualquier pérdida de material genético menor que un cromosoma. Puede afectar a un brazo de un cromosoma, a un gen, o a un pequeño número de pares de bases. Amplificación: Se trata de la presencia de varias copias de un gen cuya estructura es normal. Translocación: Una translocación es el intercambio de material genético entre dos cromosomas no homólogos. Lo más frecuente es que no se pierda material genético sino que éste simplemente cambie de lugar; en este caso hablamos de translo- caciones balanceadas. Inversión: Una inversión es el resultado de dos roturas en un cromosoma seguidas por la reinserción del fragmento original pero en orden inverso. Mutación puntual: Es un tipo de mutación en el que una base es sustituida por otra.

Síndromes familiares. Aunque la mayoría de las mutaciones aparecen de forma esporádica, existen sin embargo cuatro síndromes bien caracterizados de cáncer familiar asociado a sarcoma. En primer lugar los pacientes con mutaciones de RB en la línea germinal tienen una frecuencia de aparición de osteosarcomas muy superior a la de la población general $^{3}$. Los pacientes con síndrome de Li-Fraumeni, con mutaciones de la línea germinal del gen p $53^{4}$ tienen una incidencia elevada de un amplio grupo de sarcomas, típicamente a una edad inferior a los 40 años. Otro tipo de sarcoma, el tumor maligno de las vainas de los nervios periféricos surge frecuentemente en el seno de una neurofibromatosis tipo 1 (NF-1), que se asocia con la pérdida del gen NF1 en la línea germinal 5 . Por último se ha descrito un síndrome familiar de GIST (tumor del estroma gastrointestinal) en una familia con mutaciones germinales del gen c-kit ${ }^{6}$.

\section{Existen dos tipos de sarcomas según la complejidad de sus alteraciones moleculares}

Por una parte hay un grupo de sarcomas, más frecuente en los niños y adolescentes, cuyas alteraciones citogenéticas son relativamente sencillas, generalmente translocaciones equilibradas ${ }^{7}$. Desde el punto de vista molecular se caracterizan por fusiones génicas derivadas de dichas translocaciones, o mutaciones puntuales, que suponen la iniciación del proceso de carcinogénesis.

Un segundo grupo de sarcomas, como el osteosarcoma o el histiocitoma fibroso maligno ${ }^{8}$, se caracterizan por tener un cariotipo muy complejo, y por carecer de fusiones génicas. De hecho muestran claros signos de inestabilidad cromosómica y genómica.

Las mutaciones de genes supresores tumorales como p53, INK4A o RB se encuentran en ambos subtipos de tumores, y están relacionadas con la progresión tumoral. Es importante hacer notar que, por tanto, no tienen interés diagnóstico, pero pueden determinar el pronóstico de algunos sarcomas (ver como ejemplo Huang et al., 2005) 9 . 


\section{TABLA I}

Rasgos moleculares de interés diagnóstico en tumores mesenquimales. Obsérvese el gran número de fusiones génicas en las que forma parte el protooncogén EWS o su homólogo FUS

\begin{tabular}{|c|c|c|c|c|}
\hline Tipo tumoral & Rasgo citogenético & Rasgo molecular & Factor de transcripción & Prevalencia \\
\hline Tumor de Ewing & $\begin{array}{l}\mathrm{t}(11 ; 22)(\mathrm{q} 24 ; \mathrm{q} 12) \\
\mathrm{t}(21 ; 22)(\mathrm{q} 22 ; \mathrm{q} 12) \\
\mathrm{t}(7 ; 22)(\mathrm{p} 22 ; \mathrm{q} 12) \\
\mathrm{t}(2 ; 22)(\mathrm{q} 33 ; \mathrm{q} 12) \\
\mathrm{t}(1 ; 22)(\mathrm{q} 42 ; \mathrm{q} 12) \\
\mathrm{t}(2 ; 22)(\mathrm{q} 33 ; \mathrm{q} 12) \\
\mathrm{t}(17 ; 22)(\mathrm{q} 12 ; \mathrm{q} 12) \\
\mathrm{t}(6 ; 22)(\mathrm{p} 21 ; \mathrm{q} 12)\end{array}$ & $\begin{array}{l}\text { EWS-FLI1 } \\
\text { EWS-ERG } \\
\text { EWS-ETV1 } \\
\text { EWS-E1AF } \\
\text { EWS-? } \\
\text { EWS-FEV } \\
\text { EWS-ETV4 } \\
\text { EWS-POU5F1 }\end{array}$ & $\begin{array}{l}\text { Sí } \\
\text { Sí } \\
\text { Sí } \\
\text { Sí }\end{array}$ & $\begin{array}{l}95 \% \\
5 \% \\
<1 \% \\
<1 \% \\
<1 \% \\
<1 \% \\
i\end{array}$ \\
\hline $\begin{array}{l}\text { T. desmoplásico de células } \\
\text { pequeñas y redondas }\end{array}$ & $\mathrm{t}(11 ; 22)(\mathrm{p} 13 ; \mathrm{q} 12)$ & $\boldsymbol{E W S}-W T 1$ & Sí & $100 \%$ \\
\hline $\begin{array}{l}\text { Liposarcoma mixoide-de } \\
\text { células redondas y liposarcoma } \\
\text { pleomórfico epitelioide }\end{array}$ & $\begin{array}{l}\mathrm{t}(12 ; 16)(\mathrm{q} 13 ; \mathrm{p} 11) \\
\mathrm{t}(12 ; 22)(\mathrm{q} 13 ; \mathrm{q} 12)\end{array}$ & $\begin{array}{l}\boldsymbol{F U} \boldsymbol{U}-\mathrm{CHOP} \\
\boldsymbol{E} \boldsymbol{W}-\mathrm{S}-\mathrm{CHOP}\end{array}$ & $\begin{array}{l}\text { Sí } \\
\text { Sí }\end{array}$ & $\begin{array}{l}95 \% \\
5 \%\end{array}$ \\
\hline $\begin{array}{l}\text { Condrosarcoma mixoide } \\
\text { extraesquelético }\end{array}$ & $\begin{array}{l}\mathrm{t}(9 ; 22)(\mathrm{q} 22 ; \mathrm{q} 12) \\
\mathrm{t}(9 ; 17)(\mathrm{q} 22 ; \mathrm{q} 11)\end{array}$ & $\begin{array}{l}\boldsymbol{E W S}-C H N(T E C) \\
\boldsymbol{h T A F I I 6 8 - C H N ( T E C )}\end{array}$ & $\begin{array}{l}\text { Sí } \\
?\end{array}$ & $75 \%$ \\
\hline $\begin{array}{l}\text { Sarcoma de células claras e } \\
\text { histiocitoma fibroso angiomatoide }\end{array}$ & $\mathrm{t}(12 ; 22)(\mathrm{q} 13 ; \mathrm{q} 21)$ & $\boldsymbol{E W S}-A T F 1$ & Sí & $91 \%$ \\
\hline Sarcoma sinovial & $\begin{array}{l}\mathrm{t}(\mathrm{X} ; 18)(\mathrm{p} 11.23 ; \mathrm{q} 11) \\
\mathrm{t}(\mathrm{X} ; 18)(\mathrm{p} 11.21 ; \mathrm{q} 11) \\
\mathrm{t}(\mathrm{X} ; 18)(\mathrm{p} 11 ; \mathrm{q} 11) \\
\mathrm{t}(\mathrm{X} ; 20)(\mathrm{p} 11 ; \mathrm{q} 13.3)\end{array}$ & $\begin{array}{l}\text { SS18-SSX1 } \\
\text { SS18-SSX2 } \\
\text { SS18-SSX4 } \\
\text { SS18L1-SSX1 }\end{array}$ & $\begin{array}{l}\text { Sí } \\
\text { Sí } \\
\text { Sí } \\
\text { Sí }\end{array}$ & $\begin{array}{l}65 \% \\
35 \%\end{array}$ \\
\hline $\begin{array}{l}\text { Tumor del estroma } \\
\text { gastrointestinal (GIST) }\end{array}$ & varias & Mutaciones de KIT & No & $95 \%$ \\
\hline Tumor rabdoide extrarrenal & Deleción de 22q & Inactivación de INI & $?$ & $>90 \%$ \\
\hline Rabdomiosarcoma alveolar & $\begin{array}{l}\mathrm{t}(2 ; 13)(\mathrm{q} 35 ; \mathrm{q} 14) \\
\mathrm{t}(1 ; 13)(\mathrm{p} 36 ; \mathrm{q} 14) \\
\mathrm{t}(2 ; 2)(\mathrm{q} 35 ; \mathrm{p} 23)\end{array}$ & $\begin{array}{l}\text { PAX3-FKHR } \\
\text { PAX7-FKHR } \\
\text { PAX3-NCOA1 }\end{array}$ & $\begin{array}{l}\text { Sí } \\
\text { Sí } \\
\text { Sí }\end{array}$ & $\begin{array}{l}75 \% \\
10 \%\end{array}$ \\
\hline Dermatofibrosarcoma protuberans & $\mathrm{t}(17 ; 22)(\mathrm{q} 22 ; \mathrm{q} 13)$ & COL1A1-PDGFB & No & \\
\hline $\begin{array}{l}\text { Fibrosarcoma infantil/ } \\
\text { Nefroma mesoblástico celular }{ }^{1}\end{array}$ & $\mathrm{t}(12 ; 15)(\mathrm{p} 13 ; \mathrm{q} 25)$ & ETV6-NTRK3 & No & \\
\hline $\begin{array}{l}\text { Sarcoma alveolar de tejidos } \\
\text { blandos }\end{array}$ & $\operatorname{der}(17) t(X ; 17)(p 11 ; q 25)$ & TFE3-ASPL & Sí & \\
\hline $\begin{array}{l}\text { Sarcoma del estroma endome } \\
\text { trial de bajo grado }\end{array}$ & $\mathrm{t}(7 ; 17)(\mathrm{p} 15 ; \mathrm{q} 21)$ & JAZF1-JJAZF1 & Sí & $?$ \\
\hline $\begin{array}{l}\text { Tumor miofibroblástico } \\
\text { inflamatorio }\end{array}$ & $\begin{array}{l}\mathrm{t}(1 ; 2)(\mathrm{q} 21 ; \mathrm{p} 23) \\
\mathrm{t}(2 ; 17)(\mathrm{p} 23 ; \mathrm{q} 23)\end{array}$ & $\begin{array}{l}\text { TPM3/TPM4-ALK } \\
\text { CLTC2-ALK }\end{array}$ & Sí & \\
\hline $\begin{array}{l}\text { Sarcoma fibromixoide } \\
\text { de bajo grado }\end{array}$ & $\mathrm{t}(7 ; 16)(\mathrm{q} 32 ; \mathrm{p} 11)$ & FUS-CREB3L1(2) & Sí & \\
\hline Tumores benignos $^{3}$ & $\begin{array}{l}\text { Alteraciones } 12 \mathrm{q} 15 \\
\text { Alteraciones } 6 \mathrm{p} 21\end{array}$ & $\begin{array}{l}\text { Alteraciones } \\
H M G I-C \text { y } H M G I(Y)\end{array}$ & No & \\
\hline
\end{tabular}

\footnotetext{
${ }^{1}$ Fusión también presente en algunos carcinomas secretores de mama.

${ }^{2}$ Fusión análoga a la presente en algunos carcinomas renales infantiles o de adultos jóvenes.

${ }^{3}$ Lipoma, hamartoma condroide pulmonar, adenoma pleomorfo, fibroadenoma de mama, leiomioma uterino, pólipo endometrial, angiomixoma agresivo, mesenquimoma benigno.
} 


\section{E. de Álava}

\section{Existen dos tipos de mutaciones con valor clínico en los sarcomas}

Translocaciones. Varios tipos de sarcomas muestran translocaciones características. De hecho, es en este tipo de tumores donde se han realizado los mayores avances en el conocimiento de su patogenia ${ }^{7}$. Las fusiones génicas generadas a partir de las translocaciones son los acontecimientos iniciadores de muchos sarcomas, y son probablemente indispensables en algunos subtipos de ellos ${ }^{10}$. Estas translocaciones interrumpen ciertos genes, y los recombinan creando fusiones génicas con estructura y función nuevas porque combinan dominios funcionales que habitualmente se encuentran en moléculas separadas. La mayor parte de las proteínas quiméricas son factores de transcripción; es decir, proteínas con capacidad de unión a las regiones reguladoras de la transcripción de ciertos genes. Éstos están habitualmente implicados en ciertas funciones clave para la célula, como la proliferación o la supervivencia celulares. Como resultado de las translocaciones, las fusiones génicas representan casi siempre factores de transcripción aberrantes. Las dos excepciones más notables son la COL1A1-PDGFB del dermatofibrosarcoma protuberans, que es un factor de crecimiento y la ETV6NTRK3 del fibrosarcoma congénito, que corresponde a una proteína con actividad tirosina quinasa ${ }^{7}$. Puesto que las fusiones génicas y sus productos son específicos de cada tipo tumoral y se observan en prácticamente todos los casos de muchos tipos de sarcomas su caracterización no es sólo importante desde el punto de vista de la patogenia, sino que abre grandes posibilidades diagnósticas y terapéuticas. (Tabla I).

Mutaciones puntuales. Otro tipo de hallazgos específicos de los sarcomas son las mutaciones, como por ejemplo las mutaciones activadoras de c-kit en el GIST, o las mutaciones inactivantes de hSNF5/ INI1 en tumores rabdoides.

\section{Aplicación al diagnóstico. Translocaciones}

\section{Técnicas empleables para detectar translocaciones}

La $R T-P C R$ es el método más empleado para la detección de translocaciones en muestras clínicas, especialmente cuando contamos con muestras con-
RNA

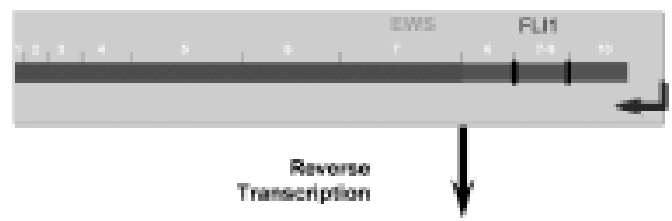

cDNA

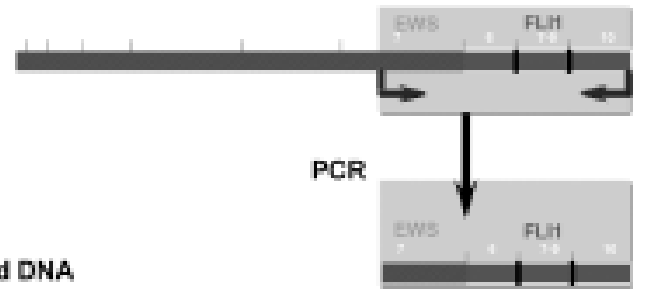

Amplified DNA

Figura 1. RT-PCR

Esta técnica tiene dos pasos. En el primero (mitad superior de la figura) el ARN se retro-transcribe a cADN y en el segundo (mitad inferior), se amplifica un segmento específico de cADN que contiene la zona de fusión génica. El ejemplo corresponde a la fusión EWS-FLI1, característica del tumor de Ewing, pero la situación es análoga a casi todos los sarcomas con translocaciones.

geladas de tumores (Figura 1). Esta técnica tiene dos pasos; en el primero se usa la transcriptasa inversa (RT), un enzima que sintetiza cADN a partir de ARN. En un segundo paso se amplifica el cADN mediante una PCR convencional empleando como cebadores secuencias características de los exones que flanquean los puntos de rotura de las translocaciones. Se realiza una electroforesis de los productos de PCR en un gel de agarosa. Opcionalmente el ADN contenido en el gel de agarosa se puede transferir a una membrana de nylon e incubar con sondas de ADN complementarias a la secuencia esperada (Southern blot). Esto incrementa la sensibilidad y la especificidad. Evidentemente hay que emplear controles positivos y negativos (con agua y sin RT). Algunos autores proponen el uso de RT-PCR cuantitativa para el diagnóstico ${ }^{11}$.

Los puntos de rotura de las translocaciones tienen lugar habitualmente en ciertos intrones; sin embargo el lugar dentro de cada intrón donde tiene lugar dicha rotura es muy variable. El resultado de este hecho es que la estructura de la fusión a nivel del ADN genómico es bastante menos predecible que a nivel del ARN, donde tiene un número más constante de exones de cada uno de los genes implicados en la fusión. Esta es la razón por la que es preferible el ARN como material de partida para la detección de translocaciones en sarcomas mediante la RT-PCR. 


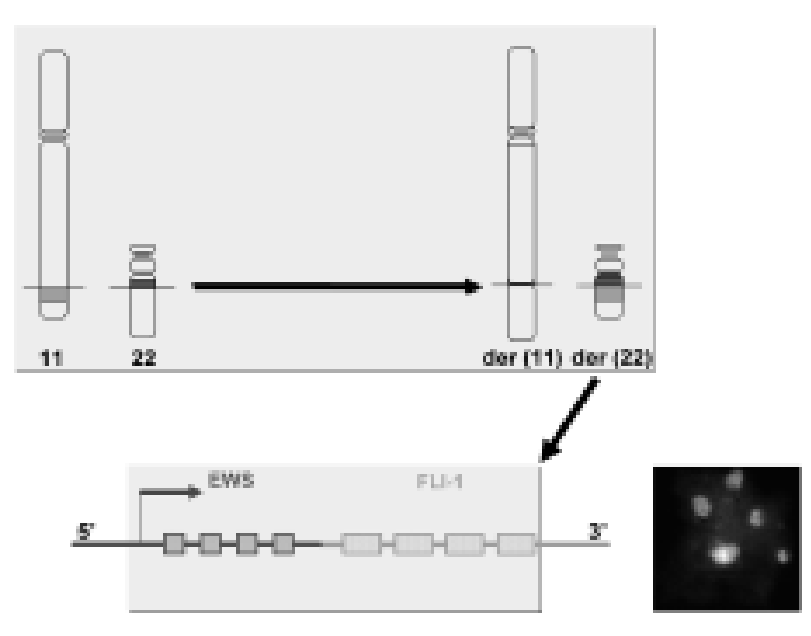

Figura 2. FISH. (Hibridación in situ con fluorescencia).

El FISH puede usarse para identificar translocaciones en muestras tisulares o citológicas mediante el uso de sondas fluorescentes. En este caso particular de un FISH para la detección de fusiones génicas, el gen EWS, situado en el cromosoma 22, está representado en rojo, mientras que el FLI1 lo está en verde. La parte superior del diagrama muestra cómo la translocación reordena ambos genes, y la parte inferior representa la propia fusión. Se muestra una imagen en la esquina inferior derecha de un experimento de FISH en un tumor de Ewing que corresponde a una célula triploide en la que se observan dos señales rojas y dos señales verdes, correspondientes a los alelos no reordenados, junto a una imagen de fusión, de color rojo-amarillento.

Por eso hacemos hincapié en la creación y mantenimiento de bancos de tumores, porque la mejor fuente para conseguir ARN de calidad es el material congelado.

Otros métodos diagnósticos incluyen la citogenética convencional y la hibridación in situ con fluorescencia (FISH) (Figura 2). La palabra 'hibridación' se refiere a la unión de secuencias de ADN o ARN complementarias. Las sondas se marcan con moléculas fluorescentes, que son por tanto útiles para detectar las secuencias de interés. Las sondas que se emplean en el estudio de tumores mesenquimales son habitualmente sondas específicas de una secuencia, como por ejemplo las que flanquean los puntos de rotura de las translocaciones. Para detectar las secuencias hace falta emplear al menos dos sondas, una para cada uno de los genes implicados, cada una marcada con un fluorocromo diferente. A veces las sondas están diseñadas para detectar la presencia de fusiones (fusion signal probes), y en otras ocasiones lo que se busca es simplemente ver si se ha produci- do un reordenamiento de uno de los genes implicados en la fusión (split signal probes). El FISH tiene la ventaja de que puede dar resultados fiables cuando la cantidad de tejido disponible es escasa o cuando hay sólo material de parafina, y puede ser usada incluso en matrices tisulares ${ }^{12}$, o cuando sólo se cuenta con improntas de tejido tumoral. El inconveniente es que hace falta un microscopio de fluorescencia, lo que hace que el FISH sea una técnica difícilmente integrable en un laboratorio pequeño de Patología. La técnica de $C I S H$, en la que se sustituye la inmunofluorescencia por un cromógeno (similar a los empleados en inmunohistoquímica) se emplea ya en rutina diagnóstica para la detección de amplificaciones génicas pero tiene mal rendimiento para la detección de translocaciones ${ }^{12}$ y podría en el futuro emplearse para la detección de translocaciones en sarcomas.

Algunos (pocos) tipos de fusiones se pueden detectar con inmunohistoquímica. Por ejemplo en el tumor desmoplásico de células pequeñas y redondas, en el que se detecta una fusión que incluye el extremo aminoterminal de EWS y el carboxiloterminal de WT1, se puede realizar inmunohistoquímica con anticuerpos dirigidos al dominio amino y carboxilo terminal de $\mathrm{WT} 1{ }^{13}$. La intensa inmunorreactividad con éste último, y la ausencia con el primero ayudan a detectar la fusión. De modo análogo la fusión NPM-ALK se puede detectar en el $60 \%$ de los tumores miofibroblásticos inflamatorios, en los que detectamos la sobreexpresión del dominio carboxilo de ALK con un anticuerpo específico ${ }^{14}$, mientras que en otras lesiones morfológicamente similares (fascitis nodular, fibromatosis) no se encuentra inmunorreactividad para ALK. Aunque en la práctica es difícil encontrar los epitopos específicos, esta sistemática podría emplearse con algunas de las translocaciones presentes en los sarcomas.

\section{Detección de translocaciones en material clínico}

Una gran ventaja de las técnicas de Patología Molecular es que, a pesar de contar a veces con una biopsia pequeña o con morfología distorsionada, o carente de diferenciación, las células tumorales conservan las alteraciones moleculares básicas, y su detección puede ofrecer seguridad en un determinado diagnóstico. Se pueden detectar dichas translocaciones en material fijado en formol e incluido en parafi- 


\section{E. de Álava}

$n a^{15}$. Dependiendo de la experiencia de los autores, la RT-PCR es capaz de detectarlas en aproximadamente el 50\% de los casos, extrayendo el ARN con un tratamiento proteolítico más largo del habitual y empleando cebadores que delimiten un producto de PCR muy corto. Por ejemplo, el grupo francés de sarcomas ${ }^{16}$ demuestra en un estudio que incluye detección de fusiones SYT-SSX, características del sarcoma sinovial, en 250 tumores fijados con varios fijadores habituales e incluidos en parafina, que la sensibilidad de la técnica es superior al 95\% (siempre que los tejidos no se fijen con Bouin) y que su especificidad es del $100 \%$. El rendimiento del FISH es al menos similar al de la RT-PCR en material parafinado ${ }^{15}$.

El material citológico, tanto las extensiones como el material obtenido mediante punción aspiración con aguja fina, son una excelente fuente de ARN de alta calidad para estudios citogenéticos y molecula$\operatorname{res}^{17,}{ }^{18}$. Habitualmente, una vez asegurado el diagnóstico, realizamos una toma adicional para los estudios moleculares. La RT-PCR y, especialmente, el FISH son técnicas que se pueden aplicar con facilidad en muestras citológicas de tumores mesenquimales.

\section{Translocaciones más relevantes y sus tipos tumorales}

Las fusiones EWS-FLII se detectan en aproximadamente $85 \%$ de los tumores de Ewing; las EWS$E R G$ están presentes en $10 \%$ de los casos, mientras que un 3\% corresponde a otros tipos de fusiones de EWS con un miembro de la familia ETS de factores de transcripción. Se trata de un dato específico de esta neoplasia ya que los estudios mediante PCR de otros tumores que podrían entrar en su diagnóstico diferencial, como los tumores neuroectodérmicos primitivos centrales, neuroblastomas, rabdomiosarcomas, adamantinomas o tumores de células gigantes óseos ${ }^{10}$.

Además de los factores pronósticos habituales en esta neoplasia (estadio, localización/volumen del tumor primario, edad y respuesta al tratamiento) hay estudios recientes que evalúan la contribución de la heterogeneidad molecular al pronóstico en el tumor de Ewing. Existen al menos 18 posibilidades estructurales de las fusiones génicas en esta neoplasia. Hay dos fuentes de variabilidad (Figura 3). Por un lado el 'compañero' de fusión de EWS (FLI1, ERG,

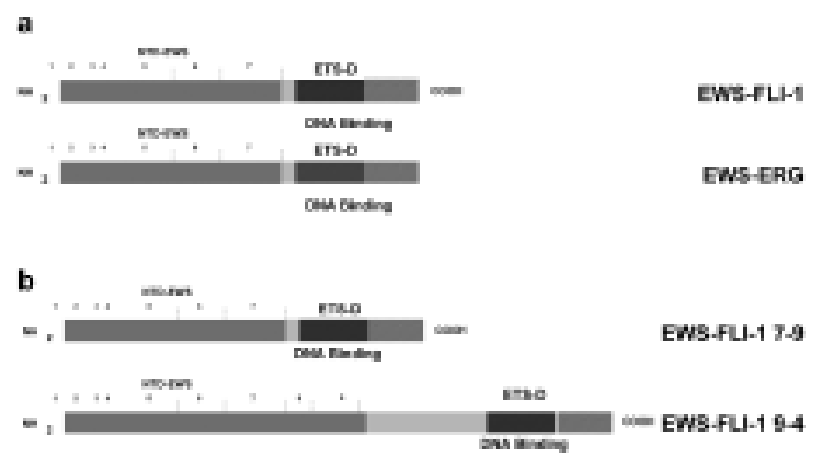

Figura 3. Estructura de las proteínas quiméricas y su variabilidad.

La estructura de las fusiones quiméricas que se encuentran en el tumor de Ewing es un ejemplo de la que se observa en la mayoría de las proteínas quiméricas de los sarcomas. Las proteínas quiméricas EWS-FLI1 o EWS-ERG contienen el dominio amino-terminal de EWS (en gris), unido a la zona carboxilo-terminal de FLI1 o ERG (en negro). Este último contiene el dominio ETS de unión a ADN (punteado blanco en FLI1, bandas diagonales en ERG). Los números pequeños representan los exones que participan en la fusión. La variabilidad de fusiones génicas en el tumor de Ewing depende en primer lugar del gen que acompaña a EWS en la fusión.

b. En segundo lugar, para un tipo concreto de fusión (aquí se representa la EWS-FLI1) existen varias posibilidades dependiendo del número de exones de cada uno de los genes que participan en la fusión. La mitad superior de esta sección muestra la fusión más corta (EWS ex.7-FLI1 ex. 9), mientras que la inferior muestra la más larga (EWS ex.9-FLI1 ex.4). La estructura de las fusiones génicas en el tumor de Ewing se correlaciona con el pronóstico (ver texto).

ETV1, E1A,o FEV), y por otro la localización del punto de rotura de la translocación dentro de cada uno de los genes implicados. Se ha comprobado que los pacientes con tumor de Ewing localizado que expresan el transcrito quimérico más común (EWS exón 7 unido a FLI1 exón 6) tienen mejor pronóstico que los que tienen cualquier otro tipo de fusión ${ }^{19}$. Esto sugiere que la heterogeneidad en la estructura de los transcritos pueda definir de manera clara diferentes grupos de riesgo. La base biológica por la que se observan estas diferencias en pronóstico no está clara, aunque se ha demostrado que las diferentes fusiones génicas son factores de transcripción con diferente actividad transactivadora ${ }^{20}$. De todos modos, la validación de estos resultados está pendiente de estudios clínicos prospectivos donde se determina el tipo de fusión de cada tumor, como por ejemplo el EuroEwing99, cuyos resultados definitivos desconocemos por el momento. 
En el tumor desmoplásico de células pequeñas y redondas (TDCPR) el gen EWS se halla unido al gen WT1. WT1 se conoció en primer lugar como un gen supresor tumoral alterado en el tumor de Wilms, y de hecho EWS-WT1 es el primer ejemplo de un reordenamiento constante de un gen supresor tumoral. El transcrito quimérico EWS-WT1 se ha encontrado en el $97 \%$ de los casos estudiados. Este hecho lo hace muy útil para el diagnóstico ${ }^{21}$, pero además sugiere que la proteína quimérica es importante para el desarrollo del tumor. Como en muchos otros sarcomas se trata de un factor de transcripción aberrante, que modula la expresión de genes que coinciden parcialmente con las dianas habituales del gen WT1. Uno de ellos es PDGFA, un factor de crecimiento fibroblástico que probablemente contribuye a la fibrosis tan característica de esta neoplasia ${ }^{22}$. Otro es BAIAP3, que regula el proceso de exocitosis, y por tanto el de secreción de factores de crecimiento ${ }^{23}$.

EWS se une a ATF1 en el sarcoma de células claras (melanoma maligno de tejidos blandos) ${ }^{24}$, y en el histiocitoma fibroso angiomatoide ${ }^{25}$. Al igual que en el tumor de Ewing, EWS se une al dominio de unión a $\mathrm{ADN}$ de un factor de transcripción. Al contrario que ATF1, la fusión EWS-ATF1 funciona como un activador transcripcional, probablemente alterando la regulación de los genes controlados habitualmente por ATF1. El ARN quimérico se detecta tanto en fragmentos de tumor congelado como en material fijado en parafina ${ }^{26}$.

La fusión EWS-CHN, generada a partir de una $\mathrm{t}(9 ; 22)$, se observa en el condrosarcoma mixoide extraesquelético, curiosamente no en el de origen óseo ${ }^{27}$. CHN codifica un receptor nuclear con un dominio de unión a ADN. La proteína de fusión contiene el dominio aminoterminal de EWS unido a todo el marco de lectura de $\mathrm{CHN}$, lo que origina un receptor nuclear más activo que el nativo. Dicho receptor está implicado en el control de la proliferación celular al modular la respuesta a diversos factores de crecimiento. Existen algunas variantes poco frecuentes de esta fusión. Los estudios de genómica han señalado que este tumor tiene alta expresión de PPARG, para el que existen inhibidores específicos, y podría ser una diana terapéutica ${ }^{28}$.

Además, un gen análogo a EWS, FUS, está implicado con CHOP (DDIT3) en fusiones geíncas en el 90\% de los casos de liposarcoma mixoidelde células redondas (FUS-CHOP) ${ }^{29}$. CHOP (DDIT3) es un factor de transcripción. En TLS-CHOP (FUSDDIT3) el dominio de unión a ARN de TLS se reemplaza por el dominio de unión a ADN de CHOP. La relación entre el liposarcoma mixoide y el de células redondas se confirma por la detección de fusiones FUS-CHOP en tumores compuestos en parte o del todo por células redondas ${ }^{29}$. Aproximadamente el 5\% de los casos muestran fusiones EWS-CHOP, en las que EWS tiene un papel análogo a FUS. Por tanto las proteínas con capacidad de unión a ARN FUS y EWS parecen ser funcionalmente similares, mientras que el componente que aporta el dominio de unión a ADN, CHOP, es específico de esta neoplasia. El único modelo animal transgénico de cáncer mesenquimal se ha desarrollado precisamente con la fusión FUS-DDIT3 ${ }^{30}$.

El rabdomiosarcoma alveolar se asocia a una translocación frecuente, $\mathrm{t}(2 ; 13)$ y una menos habitual $\mathrm{t}(1 ; 13)$, cuyo resultado en una fusión de los genes $P A X 3$ y $P A X 7$, respectivamente, con el FKHR (forkhead in rhabdomyosarcoma) situado en $13 \mathrm{q} 14^{31}$. Los genes PAX son factores de transcripción regulados durante el desarrollo embrionario, y que son necesarios para la génesis de ciertos órganos. En particular PAX3 y PAX7 se expresan en el tubo neural, y son clave tanto para la correcta formación de éste, como para la migración de los mioblastos a las extremidades superior e inferior. PAX3 puede suprimir la diferenciación de los mioblastos, y esto podría contribuir al fenotipo indiferenciado de este tipo tumoral. Se ha detectado amplificación de las fusiones génicas en algunos tumores con fusiones PAX7-FKHR, indicando que la translocación y la amplificación pueden ser mecanismos secuenciales y complementarios en la oncogénesis de esta neoplasia. En el caso de la fusión PAX3-FKHR se detecta sobreexpresión de origen transcripcional de PAX3 no asociada a amplificación génica ${ }^{32}$. Estas diferencias en el mecanismo de sobreexpresión de PAX3 y PAX7 son análogas a las que se observan a nivel clínico. Los tumores con PAX7-FKHR tienden a surgir en pacientes más jóvenes, asociarse a una menos tasa de metástasis y a una mejor supervivencia que los que tienen fusiones PAX3FKHR $^{33}$, a pesar de tener una morfología similar.

Sarcoma sinovial. Se caracteriza por tener una $\mathrm{t}(\mathrm{X} ; 18)$, que origina una fusión entre el gen SS18 (SYT) en el cromosoma 18, con el gen SSX, del que existen dos copias, SSX1 y SSX2, que están situadas 


\section{E. de Álava}

TABLA II

Fusiones génicas que desencadenan actividad tirosina quinasa

\begin{tabular}{|llc|}
\hline Tumor & Proteína & Tratable con Imatinib? \\
\hline Dermatofibrosarcoma protuberans & COL1A1-PDGFB & Sí \\
Fibrosarcoma infantil & ETV6-NTRK3 & No \\
Tumor miofibroblástico inflamatorio & TMP3/TPM4/CLTC2-ALK & No \\
\hline
\end{tabular}

${ }^{1}$ A través de PDGFR.

en dos subregiones del cromosoma Xp11 (23 y 21, respectivamente); existen algunas fusiones más raras. La fusión codifica un factor de transcripción nuclear anormal, que altera la remodelación de la cromatina, lo que puede inducir a cambios en los patrones de expresión génica. Los transcritos se detectan en casi todos los sarcomas sinoviales mediante RTPCR. El sarcoma sinovial es un claro ejemplo de correlación entre fenotipo tumoral y tipo de transcrito. El sarcoma sinovial bifásico se asocia con fusiones SYT-SSX1, presentes tanto en los elementos epiteliales como en los fusocelulares, mientras que el monofásico habitualmente se presenta con SYT-SSX2. Además a nivel clínico los pacientes con SYT-SSX2 tienen un riesgo relativamente bajo de recidivas, mientras que los tumores con la variante SYT-SSX1 tienen una alta tasa proliferativa y un pronóstico relativamente peor $^{34,35}$, aunque el valor pronóstico de estas fusiones aún está bajo discusión ${ }^{36}$.

La translocación $\mathrm{t}(17 ; 22)$ del dermatofibrosarcoma protuberans y del fibroblastoma de células gigantes genera una fusión que implica a COL1A1, un gen del colágeno, y PDGFB, un gen que codifica una proteína cuya función es la de factor de crecimiento. La fusión coloca a PDGFB bajo el control del promotor de COL1A1, eliminando todos los elementos que reprimen la transcripción de PDGFB. En el fibrosarcoma congénito, la translocación $\mathrm{t}(12 ; 15)$ junta al gen ETV6 (TEL) con el NTRK3 (receptor de la neurotrofina3 (TRKC) $^{37}$. Curiosamente esta fusión también se observa específicamente en el nefroma mesoblástico, la leucemia mieloblástica aguda y el carcinoma secretor de mama, una variante rara del carcinoma ductal infiltrante mamario ${ }^{38}$. Estos dos ejemplos de fusiones suponen una excepción a la regla general de que las fusiones génicas originan facto- res de transcripción nuevos ETV6-NTRK3 es una tirosina quinasa quimérica que puede contribuir a la oncogénesis mediante la desregulación de las vías de transducción de señales generadas por NTRK3, mientras que PDGFB-COL1A1 actúa probablemente como un factor de crecimiento autocrino.

La determinación de los mecanismos moleculares implicados en la génesis de los diferentes sarcomas puede tener a partir de ahora consecuencias importantes en la mejora del tratamiento de los pacientes con dichas neoplasias. La razón es que se pueden diseñar fármacos que incidan específicamente en algunas de dichas alteraciones génicas. Como hemos dicho algunas proteínas quiméricas tienen actividad tirosina quinasa; algunas de ellas pueden responder a Imatinib (Gleevec). Por ejemplo se han publicado varios ensayos clínicos de tratamiento del dermatofibrosarcoma protuberans mediante Imatinib, con una excelente tasa de respuesta ${ }^{39}$; recordemos que este tumor sobre expresa una tirosín quinasa frente a la que Imatinib tiene una intensa acción ${ }^{40}$. Otras proteínas quiméricas se beneficiarán probablemente de fármacos nuevos (Tabla II).

\section{Detección de enfermedad residual}

La RT-PCR es extremadamente específica y sensible, y permite la detección de niveles muy bajos de células tumorales, incluso cuando se presentan mezcladas con un número alto de células normales, como ocurre en las muestras de médula ósea o de sangre periférica. Se trata por tanto de un método muy sólido para realizar un estadiaje molecular o para monitorizar la respuesta al tratamiento. Puesto que el estadio tumoral es la variable con más valor pronóstico en los sarcomas, la determinación mediante 
RT-PCR de la presencia de células con transcritos quiméricos tiene una aplicación clínica de indudable potencial. De hecho cabe suponer que algunos pacientes cuya enfermedad aparece localizada, puedan tener un pronóstico desfavorable debido a la presencia de enfermedad metastásica mínima no detectable mediante métodos tradicionales. Existen por ejemplo varios grupos que demuestran que la detección de células con fusiones EWS-FLI1 o EWS-ERG en sangre periférica o médula ósea de pacientes con enfermedad localizada se asocia a la presencia de progresión tumoral o recidivas sistémicas de tumor de Ewing ${ }^{41}$. Se han observado resultados similares mediante la detección de fusiones PAX3-FKHR, características del rabdomiosarcoma alveolar ${ }^{42}$. Hace falta, sin embargo, responder todavía a un gran número de cuestiones metodológicas y clínicas para conocer qué implicaciones pronósticas y terapéuticas tiene la detección de enfermedad circulante mediante RTPCR.

\section{Utilidad diagnóstica principal: presentaciones clínicas inhabituales}

Es evidente que el diagnóstico anatomopatológico de la mayoría de los sarcomas se realiza sin demasiadas dificultades cuando se presenta en su contexto clínico-patológico habitual (edad, localización, etc). Sin embargo el estudio de las fusiones génicas en muestras clínicas es de gran utilidad cuando las neoplasias tienen una presentación clínica poco habitual (Figura 4). Por citar el ejemplo del tumor de Ewing, su diagnóstico se puede confirmar mediante las técnicas moleculares cuando aparece en localizaciones primarias poco habituales (p.ej. epífisis ósea, riñón, piel), o en grupos de edad no convencionales (inferior a 5 años, superior a 40 años) ${ }^{7}$.

\section{Otras utilidades: clasificación de entidades}

1. Hoy aceptamos que el sarcoma de Ewing y el Tumor neuroectodérmico primitivo periférico (TNEP) de hueso y tejidos blandos son la misma entidad, con un grado variable de diferenciación neural, debido, fundamentalmente, a que comparten una misma fusión (por ejemplo EWSFLI1, por citar la más frecuente $)^{20}$.

2. Las fusiones TLS-CHOP están presentes tanto en el liposarcoma de células redondas como en

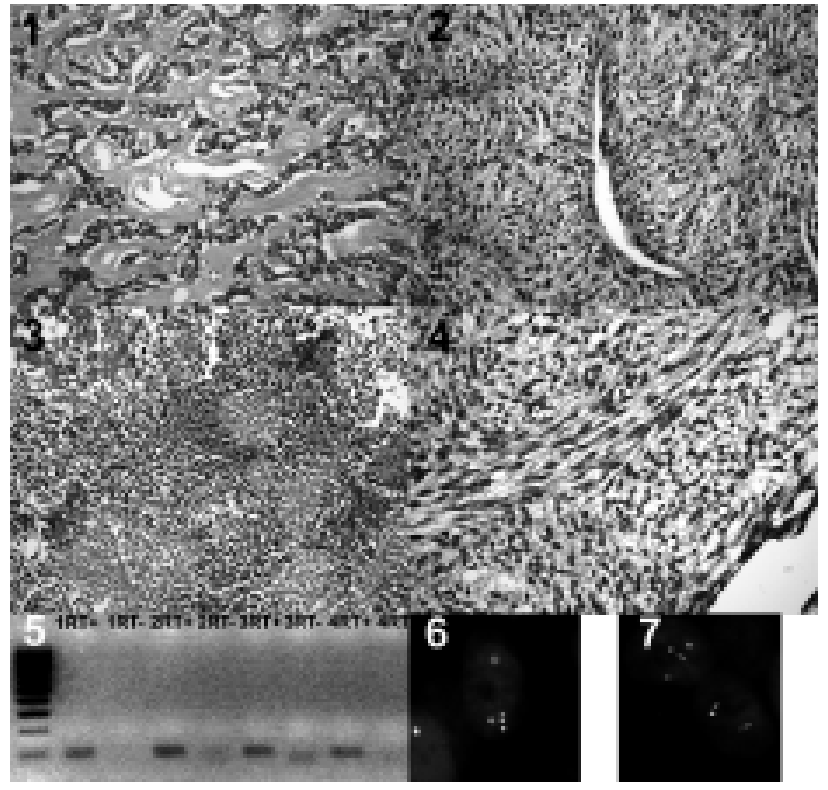

Figura 4. La detección de translocaciones es particularmente útil en la rutina diagnóstica cuando los sarcomas aparecen en situaciones clinicopatológicas poco comunes.

La composición refleja 4 casos de sarcoma sinovial. El primero corresponde a un sarcoma sinovial pobremente diferenciado en el tobillo de un niño de 5 años; el diagnóstico diferencial incluía un mioepitelioma de partes blandas y un tumor de Ewing. El caso 2, que corresponde a una niña de 7 años, tenía un patrón hemangiopericitoide llamativo, y en el diagnóstico diferencial se incluía un hemangiopericitoma infantil. El caso 3 afectaba a los tejidos blandos de la pierna de una mujer de 24 años, y correspondía a un tumor de células redondas en buena parte necrótico; se sospechaba que pudiera ser un tumor de Ewing. El caso 4 es un sarcoma sinovial que crece en la mandíbula de un varón de 66 años. La imagen 5 muestra el estudio de RT-PCR para las fusiones SYTSSX2; en todos los casos se observa una amplificación de un segmento de 110 pares de bases. Se usaron los adecuados controles negativos de la RT. La imagen 6 muestra el estudio de FISH del caso 1 con sondas de rotura de EWS (ver explicación en el texto), mostrando que EWS no está reordenado en este tumor. La imagen 7 muestra un estudio análogo para el caso 3.

el liposarcoma mixoide, lo que confirma que se trata de la misma entidad, algo que ya era de suponer puesto que muchas veces se ven tumores que contienen áreas con los dos patrones.

3. La mayoría de los condrosarcomas mixoides extraesqueléticos tienen la fusión EWS-CHN, que está ausente en los condrosarcomas mixoides óseos. Este hecho, unido a ciertas diferencias clinicopatológicas sugiere que se trata de entidades diversas. 


\section{E. de Álava}

4. Algunos rabdomiosarcomas indiferenciados, con un patrón de crecimiento sólido, que podrían ser diagnosticados como embrionarios, aparecen en localizaciones y grupos de edad típicos del rabdomiosarcoma alveolar. Tienen además la fusión $P A X 3-F K H R$, típica de este último, y representan probablemente la variante sólida del rabdomiosarcoma alveolar.

5. El tumor desmoplásico de células pequeñas y redondas, no sólo es peculiar por su presentación clínica en forma de nódulos peritoneales en adolescentes varones, y por tener un inmunofenotipo divergente, sino también porque su tienen una fusión génica característica, EWS-WT1, fue descrita prácticamente a la vez que la entidad tumoral.

\section{Falsos positivos y falsos negativos}

Aunque la correlación entre tipos tumorales y tipos de fusiones es la regla, de vez en cuando se encuentran artículos en los que se informa de la detección inesperada de cierta fusión génica en cierto tipo tumoral. Ante un hallazgo de este estilo las siguientes preguntas pueden ayudar a evaluarlo críticamente ${ }^{43}$.

1. ¿Se ha utilizado la técnica molecular adecuada? Me refiero especialmente al uso de los controles positivos y negativos adecuados que descarten una contaminación. Por ejemplo al realizar una RT-PCR conviene, además de emplear un control en el que se incluya agua en lugar de muestra, otro control en el que estén presentes todos los componentes necesarios excepto los enzimas necesarios para la amplificación.

2. ¿Se confirma el hallazgo mediante el empleo de varias técnicas alternativas? Es aconsejable, si hay material disponible, el confirmar los resultados de una PCR que muestre resultados inesperados realizando un FISH.

3. ¿Cuáles han sido los criterios empleados para realizar el diagnóstico? Especialmente en tumores poco frecuentes los criterios pueden variar entre diversas instituciones o grupos de trabajo.

4. ¿Cuál es el significado biológico de la detección de dichas fusiones? Especialmente cuando se utilizan técnicas muy sensibles el investigador puede estar empleando un umbral de detección demasiado bajo para que los resultados tengan valor biológico.
5. ¿Existe una confirmación independiente de los hallazgos por parte de otro grupo? Este es el criterio de mayor relevancia.

La presencia de un resultado negativo inesperado puede deberse a la mala calidad del material, con extensa necrosis, por ejemplo, o a la presencia de inhibidores tisulares de la reacción de PCR, o a que las translocaciones tengan un patrón complejo, que se detecte mejor mediante citogenética o FISH.

\section{Aplicación al diagnóstico. Mutaciones puntuales}

\section{Métodos de detección}

Para los estudios mutacionales el material de partida es el ADN. Puesto que éste se encuentra preservado tanto en material congelado como en el contenido en los bloques de parafina, es relativamente sencillo realizar estudios retrospectivos para la detección de mutaciones. La mayor parte de las técnicas de detección de mutaciones se basan en la PCR. Una PCR abarca habitualmente unos pocos cientos de pares de bases, por lo que hacen falta numerosas reacciones para poder estudiar por completo un gen determinado. Algunos de los genes que pueden mutarse en sarcomas, como por ejemplo RB, son grandes, y las mutaciones se pueden encontrar en cualquier área del gen, mientras que por ejemplo en el caso de p53, que es un gen relativamente pequeño, el estudio mutacional es más sencillo porque las mutaciones tienden a concentrarse en puntos concretos. En otros genes, como c-kit, se da una situación intermedia. Existen técnicas que permiten realizar un cribaje de mutaciones en productos de PCR, como el SSCP (polimorfismo de la conformación de la cadena simple de $\mathrm{ADN}$ ), pero en último término la prueba de referencia es la secuenciación del ADN. Esta se puede realizar hoy mediante secuenciadores automatizados de gran rendimiento. Otra posibilidad es el empleo de microarrays de alta densidad de oligonucleótidos; algunos de ellos pueden llevar incorporadas ciertas mutaciones puntuales. El ADN de la muestra problema se hibrida con el array, y cualquier alteración en el patrón de hibridación con respecto al de la hibridación de una secuencia "normal" informa sobre el tipo y localización de las mutacio- 
nes. Por último un método indirecto de detectar mutaciones activantes (como la de c-kit en el GIST) es la inmunohistoquímica. Esta técnica detecta la sobreexpresión de proteína KIT, que es un resultado de la mutación activadora del gen c-kit, de la que hablaremos en el apartado siguiente.

\section{Importancia práctica de la detección de mutaciones en sarcomas}

Imagino que al lector este título le evoca el ejemplo de los tumores del estroma gastrointestinal (GIST). De ser un tumor prácticamente desconocido hasta el año 2000, a pesar de haberse descrito unos diez años antes, se ha constituido como el mejor ejemplo de la aplicación clínica de la detección de mutaciones en sarcomas debido a la posibilidad de tratamiento con Imatinib. Muchos GIST expresan la oncoproteína KIT activada de manera constitutiva. La activación de dicha proteína no depende ya de la unión a su ligando, sino que la proteína KIT en el GIST sufre una serie de cambios estructurales que favorecen su activación mediante autofosforilación y oligomerización incluso en ausencia de ligando. En ausencia de ligando, la proteína KIT normal es un monómero en que ciertos dominios, fundamentalmente el yuxtamembrana (exón 11) inhiben la actividad quinasa. La activación tiene lugar cuando SCF interactúa con KIT originando su autofosforilación. Esta elimina la conformación estructural inhibitoria basal de KIT, y origina una fosforilación de KIT y de sus sustratos. Hay evidencia, sin embargo, de un pequeño número de GIST en que existen otros mecanismos de activación, como las mutaciones puntuales en PDGFRA ${ }^{44}$. Existen también algunos casos, negativos para KIT mediante inmunohistoquímica, en los que se observan mutaciones de c-kit o de PDGFR en exones compatibles con una respuesta a Imatinib, con lo que existen pacientes en los que merece la pena administrar Imatinib aún a pesar de carecer de inmunorreactividad para $\mathrm{KIT}^{45}$; se trata de tumores que surgen en el epiplón y que tienen morfología epitelioide. Puede darse también el caso inverso; existe un grupo de GIST que surgen en pacientes con neurofibromatosis tipo 1, que carecen completamente de mutaciones de c-kit o PDGFR pero que puede tener inmunorreactividad para $\mathrm{KIT}^{46}$.

Las mutaciones activadoras de KIT, tal y como se observan en el GIST, podrían dividirse en dos gran-

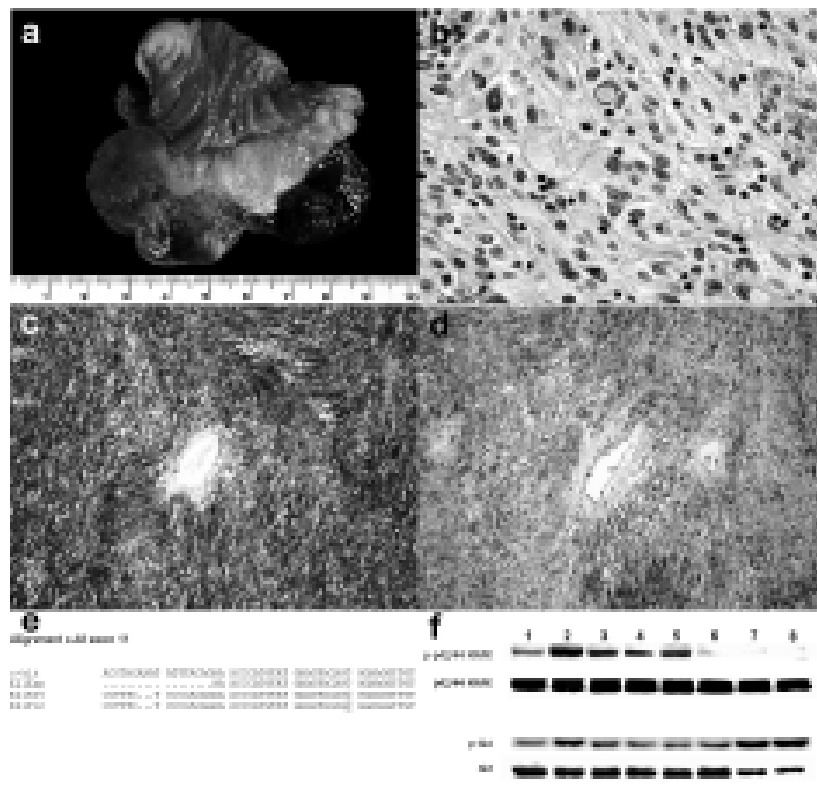

Figura 5. Patología Molecular de un GIST de intestino delgado en una mujer de 68 años.

A. Imagen macroscópica que muestra una masa carnosa que invade la pared del intestino (fotografía cortesía del Dr. Pablo Gonzalvo, Hospital de Jarrio, Asturias). B. El tumor tenía numerosas mitosis y de manera focal era epitelioide. C. Inmunorreactividad para proteína KIT total en las células tumorales. D. Inmunorreactividad usando un anticuerpo específico para detectar la forma fosforilada (activa) de KIT (residuo fosforilado $\mathrm{Tyr}^{703}$ ), mostrando una reactividad algo más débil. E. El tumor tenía una mutación puntual en el exón 11 de c-kit (codón 557, T sustituida por C). F. Análisis mediante Western blot que muestra que el tumor (calle 1) y otros casos de GIST mostraban activación de las vías de señalización de MAPK y AKT, sugiriendo otras posibles dianas terapéuticas.

des grupos ${ }^{47}$. En primer lugar las que afectan a los dominios quinasa, es decir, a la actividad enzimática. En segundo lugar las que afectan a las secuencias reguladoras (p.ej. a los dominios yuxtamembrana) y que por tanto no afectan a la actividad enzimática. La distinción entre ambos tipos de mutaciones es importante porque la inhibición de KIT por parte de ciertas moléculas terapéuticas como Imatinib (Gleevec) depende de la localización de las mutaciones de KIT. Imatinib actúa uniéndose a los dominios quinasa o enzimáticos. Se comprende que cuando c-kit tenga mutaciones que afecten a los dominios quinasa o enzimáticos, Imatinib no será eficaz al no encontrar un dominio quinasa intacto sobre el que actuar. Buena parte del éxito de Imatinib en el GIST radica en el hecho de que la mayor parte de las mutaciones 


\section{E. de Álava}

activadoras de KIT tienen lugar en el dominio regulador yuxtamembrana, lo que no afecta a los lugares de unión de Imatinib. De esto se deduce que el conocer la localización de las mutaciones de c-kit en un tumor concreto puede ser útil para predecir la respuesta del tumor a ciertos inhibidores de KIT (Figura 5). De hecho, en una serie de pacientes de GIST incluidos en un ensayo en fase II con Imatinib, se ha visto que los pacientes con mutaciones en el exón 11 de c-kit tienen un grado de respuesta a Imatinib mayor que aquellos que tienen mutaciones en otros exones o que, simplemente, no tienen mutaciones de dicho gen ${ }^{48}$. Análogamente, dos tercios de los pacientes con GIST y mutaciones en PDGFRA carecen de respuesta a Imatinib al estar las mutaciones situadas en los dominios tirosina quinasa ${ }^{49}$.

De modo análogo a lo que hemos explicado antes en el tumor de Ewing o en el sarcoma sinovial, el tipo y localización de las mutaciones de c-kit en el GIST puede tener también valor pronóstico. Por ejemplo en un estudio que incluye pacientes con GIST no tratados con Imatinib, además de los factores pronósticos clásicos, como el tamaño tumoral o el número de mitosis, los autores hallan que los pacientes cuyos tumores tienen mutaciones puntuales, que afecten a un solo codón, en el exon 11 de c-kit, tienen un pronóstico significativamente mejor que el de los pacientes cuyos tumores tienen cualquier otra mutación, incluyendo mutaciones relativamente extensas del exón 11 (deleciones o duplicaciones que afectan varios codones) $)^{50}$. Estos resultados sugieren que el tipo de mutación es un factor pronóstico independiente en el GIST.

Más allá de los GIST, otros ejemplos de aplicación pronóstica de la detección de mutaciones en sarcomas se encuentran en el sarcoma sinovial, donde se observa sobreexpresión de receptores tirosina quinasa como EGFR o HER2 ${ }^{51}$, o la previamente comentada de mutaciones de p53 y deleciones de INK4A en tumor de Ewing 9 .

\section{Aplicación al diagnóstico. Técnicas de expresión múltiple}

\section{Técnicas de expresión múltiple}

Aunque las técnicas de análisis masivo de genómica y proteómica pueden emplearse para el cribaje de mutaciones o la detección de polimorfismos, la aplicación más directa en el campo de los sarcomas es la del estudio de los perfiles de expresión génica. Aunque todas las células tienen los mismos genes, sólo el 5\% de los genes están activos en una determinada célula en un determinado momento. Por tanto el estudio de la expresión génica mediante técnicas de expresión múltiple da una información privilegiada sobre la función y el estado de una célula normal o tumoral. Sea cual sea la tecnología empleada en los estudios de expresión múltiple (arrays de cADN, o de oligonucleótidos) conviene comentar que el resultado obtenido consiste en el nivel de expresión relativo de una muestra problema respecto a la del control. Es decir, representa los cambios cuantitativos en la expresión del gen problema entre dos muestras diferentes. Estas diferencias pueden ser de hasta varios cientos de veces. La gran cantidad de datos obtenidos requiere la aplicación de técnicas de bioinformática para intentar agrupar las muestras problema estudiadas según la similaridad de sus patrones de expresión. Existen dos sistemas de agrupamiento llamados supervisado o no supervisado. En los sistemas de agrupamiento supervisado se tiene en cuenta algún conocimiento previo sobre los objetos analizados (p.ej. diagnóstico anatomopatológico) para realizar una comparación entre dos grupos de tumores que difieren en una característica concreta (p.ej liposarcoma vs. leiomiosarcoma, buena respuesta vs. mala respuesta). El análisis no supervisado, en cambio, se lleva a cabo sin tener en cuenta ningún dato conocido previamente para evitar cualquier sesgo en la clasificación ${ }^{52}$.

\section{Aplicaciones de las técnicas de expresión múltiple}

Existen todavía pocos estudios que empleen esta tecnología en sarcomas. Por ejemplo Nielsen y cols. emplearon varios tipos de microarrays de cADN para analizar 46 muestras de sarcomas de todo tipo ${ }^{53}$. Realizando en primer lugar un estudio no supervisado encuentra 5 grandes grupos de genes que se expresan de manera coordinada. Tres de ellos correspondían a los GIST, sarcomas sinoviales y schwannomas, el cuarto a un grupo de leiomiosarcomas, y el quinto a un grupo heterogéneo de tumores que incluía todos los histiocitomas fibrosos malignos, liposarcomas pleomórficos y un segundo grupo de leiomiosarcomas. Es confortante, aunque no sor- 
prendente, que un análisis no supervisado con decenas de miles de genes reproduzca bastante bien la clasificación de los sarcomas que los patólogos vienen empleando en los últimos 100 años; este análisis pone, no obstante, de manifiesto, que lo que hoy llamamos histiocitoma fibroso maligno es no es una entidad en sí, sino que representa un grupo de sarcomas de alto grado en el que también se encuentran liposarcomas o leiomiosarcomas pleomorficos. En segundo lugar Nielsen emplea un análisis supervisado (es decir, teniendo en cuenta el diagnóstico), para ver qué genes diferencian un tipo de tumor de otro. En este estudio se encuentran genes que codifican para proteínas ya conocidas y empleadas para el diagnostico diferencial de los sarcomas mediante inmunohistoquimica (p.ej. KIT para el GIST, o S-100 para los schwannomas), pero se hallan también decenas de genes cuya expresión diferencial se desconocía hasta ahora, y que por tanto podrían comenzar a emplearse a partir de ahora en el diagnóstico diferencial.

Existen estudios más bien dirigidos a grupos concretos de tumores, como un estudio reciente que apoya la clasificación del sarcoma de células claras de partes blandas como un subtipo de melanoma gracias a sus perfiles de expresión ${ }^{54}$. Otros estudios, sin embargo, ofrecen resultados contradictorios, por ejemplo en lo que respecta a la diferenciación entre el sarcoma sinovial y el tumor maligno de las vainas de los nervios periféricos (schwannoma maligno). Mientras que el estudio anteriormente mencionado de Nielsen y cols ${ }^{53}$ los separa, existe un artículo casi simultáneo ${ }^{55}$ en el que aparecen asociados en el mismo grupo.

Una nueva generación de estudios parece mostrar más utilidad práctica. Por ejemplo un estudio británico $^{56}$ es capaz de hallar unos pocos genes cuyo nivel de expresión estratifica en el momento del diagnóstico a los pacientes con leiomiosarcomas en dos grupos con una probabilidad netamente diferente de producir metástasis en el curso de su enfermedad. Un estudio que incluye 29 rabdomiosarcomas (alveolares y embrionarios) bien caracterizados desde el punto de vista citogenético, halla un grupo de genes que diferencia ambos subtipos, y, lo que es más interesante, halla un nuevo tipo de translocación al estudiar de nuevo a un paciente que no mostraba translocaciones conocidas pero se agrupaba junto a los rabdomiosarcomas alveolares ${ }^{57}$. Un artículo que pro- fundiza en el perfil genómico de los condrosarcomas mixoides extraesqueléticos han señalado que este tumor tiene alta expresión de PPARG, para el que existen inhibidores específicos, y podría ser una diana terapéutica ${ }^{28}$.

\section{¿Las técnicas de expresión múltiple son el fin de la Patología Quirúrgica?}

Las técnicas de expresión múltiple han de verse como un complemento potencialmente útil a las técnicas diagnósticas habituales ${ }^{58}$. El propósito de la tecnología microarray no es el de clasificar tumores que puedan clasificarse por métodos más sencillos, baratos y convencionales, sino el de buscar a nivel genómico, marcadores que den información nueva de tipo pronóstico o terapéutico ${ }^{59}$. Un planteamiento en el que las técnicas convencionales se vean sustituidas por las nuevas técnicas de patología molecular no nos parece, al menos a corto o medio plazo, probable.

Las contradicciones en los resultados de los estudios de genómica a las que nos referíamos antes reflejan las limitaciones que presentan hasta ahora estas técnicas, todavía muy caras, disponibles en pocos centros, en las que la reproducibilidad se afecta por el tipo de arrays empleados, los controles empleados, o el muestreo realizado en las muestras tumorales. Un estudio muy interesante y que se publicó recientemente ${ }^{60}$ hace reflexionar sobre el efecto que el muestreo de los tumores tiene en la reproducibilidad de los estudios de microarrays. A este respecto conviene hacer notar que un papel importante del patólogo es el de hacer ver que los sarcomas (y cualquier otro tipo de tumor) son entidades heterogéneas en su morfología y en sus características moleculares y que por tanto es clave para la calidad de un experimento el seleccionar cuidadosamente las áreas tumorales a estudiar. Por otro lado conviene recordar que los resultados de los estudios de expresión múltiple no son un fin en sí mismos, y que deben ser validados mediante RT-PCR o inmunohistoquímica sobre secciones de tejido.

Dicho esto creo también que las técnicas de alto rendimiento, genómicas y proteómicas, que permiten el estudio masivo de muestras tumorales humanas, van a tener previsiblemente un profundo impacto en la clasificación de los sarcomas, proporcionando nuevos marcadores diagnósticos, pronósticos y 


\section{E. de Álava}

de respuesta a fármacos. Para que se produzca este impacto en el diagnóstico, sin embargo, hay que contar con herramientas fácilmente empleables en el ámbito clínico, es decir, cuya información se pueda integrar con facilidad con la generada por las plataformas ya existentes. Las plataformas actuales, por ejemplo, no son directamente aplicables a la rutina diaria diagnóstica de un Sistema Nacional de Salud como el nuestro. La introducción de la genómica y proteómica en el campo clínico, probablemente, podrá realizarse a corto plazo a través del diseño y validación de marcadores que empleen las plataformas tecnológicas ya existentes en dicho medio como la inmunohistoquímica, el FISH o la citometría de flujo, y sólo a medio plazo mediante el diseño y validación de nuevas herramientas genómicas y proteómicas. Dicho de otro modo, es previsible que, por ejemplo, parte del gran número de marcadores derivados de los estudios de microarrays se adapten mediante la inmunohistoquímica al contexto clinico-patológico mediante el desarrollo de nuevos anticuerpos que se puedan emplear en material parafinado.

\section{Agradecimientos}

El autor agradece la colaboración de los miembros del Laboratorio de Patología Molecular-Banco de Tumores del CIC, así como la de los patólogos y oncólogos que han contribuido con sus casos de consulta; también agradece el apoyo económico de las siguientes entidades: Comisión Europea (NoE EuroBoNet), Ministerio de Sanidad (PI020828, C03-010, G03-089), Consejería de SanidadJunta de Castilla y León, Fundación Ramón Areces, y Fundación Marcelino Botín.

\section{Bibliografía}

1. Mackall CL, Meltzer PS, Helman LJ. Focus on sarcomas. Cancer Cell 2002; 2:175-8

2. de Alava E, Navarro S, Segura DI, Peris-Bonet R. Aspectos y recomendaciones sobre el funcionamiento de los bancos de tumores. Documento de consenso. http://ritsi.uv.es. 2004.

3. Abramson DH, Ellsworth RM, Kitchin FD, Tung G. Second nonocular tumors in retinoblastoma survivors. Are they radiation-induced?. Ophthalmology 1984; 91:1351-5.

4 Malkin D, Li FP, Strong LC, Fraumeni JF Jr, Nelson CE, Kim DH, Kassel J, Gryka MA, Bischoff FZ, Tainsky MA. Germ line p53 mutations in a familial syndrome of breast cancer, sarcomas, and other neoplasms. Science 1990;250:1233-8.

5. King AA, Debaun MR, Riccardi VM, Gutmann DH. Malignant peripheral nerve sheath tumors in neurofibromatosis 1. Am J Med Genet 2000;93:388-92.

6. Nishida T, Hirota S, Taniguchi M, Hashimoto K, Isozaki K, Nakamura H, Kanakura Y, Tanaka T, Takabayashi A, Matsuda H, Kitamura Y. Familial gastrointestinal stromal tumours with germline mutation of the KIT gene. Nat Genet 1998;19:323-4.

7. Ladanyi M, Bridge JA. Contribution of molecular genetic data to the classification of sarcomas. Hum Pathol 2000;31:532-538.

8. Borden EC et al. Soft tissue sarcomas of adults: state of the translational science. Clin Cancer Res 2003;9:1941-56

9. Huang HY, Illei PB, Zhao Z, et al. Ewing sarcomas with p53 mutation or p16/p14ARF homozygous deletion: a highly lethal subset associated with poor chemoresponse. J Clin Oncol 2005;23:548-58.

10. Bennicelli JL, Barr FG. Chromosomal translocations and sarcomas. Curr Opin Oncol 2002;14:412-9.

11. Peter M, Gilbert E, Delattre O. A multiplex real-time PCR assay for the detection of gene fusions observed in solid tumors. Lab Invest 2001;81:905-12.

12. Terry J, Barry TS, Horsman DE, Hsu FD, Gown AM, Huntsman DG, Nielsen TO. Fluorescence in situ hybridization for the detection of $\mathrm{t}(\mathrm{X} ; 18)(\mathrm{p} 11.2 ; \mathrm{q} 11.2)$ in a synovial sarcoma tissue microarray using a breakapart-style probe. Diagn Mol Pathol 2005;14:77-82.

13. Hill DA, Pfeifer JD, Marley EF, Dehner LP, Humphrey PA, Zhu X, Swanson PE. WT1 staining reliably differentiates desmoplastic small round cell tumor from Ewing sarcoma/primitive neuroectodermal tumor. An immunohistochemical and molecular diagnostic study. Am J Clin Pathol 2000; $114: 345-53$

14. Cook JR, Dehner LP, Collins MH, Ma Z, Morris SW, Coffin CM, Hill DA. Anaplastic lymphoma kinase (ALK) expression in the inflammatory myofibroblastic tumor: a comparative immunohistochemical study. Am J Surg Pathol 2001;25:1364-71.

15. Qian X, Jin L, Shearer BM, Ketterling RP, Jalal SM, Lloyd RV. Molecular diagnosis of Ewing's sarcoma/primitive neuroectodermal tumor in formalin-fixed paraffin-embedded tissues by RT-PCR and fluorescence in situ hybridization. Diagn Mol Pathol 2005;14:23-8.

16. Guillou L, Coindre J, Gallagher G, Terrier P, Gebhard S, de Saint Aubain Somerhausen N, Michels J, Jundt G, Vince DR, Collin F, Trassard M, Le Doussal V, Benhattar J. Detection of the synovial sarcoma translocation $\mathrm{t}(\mathrm{X} ; 18)$ (SYT;SSX) in paraffin-embedded tissues using reverse transcriptase-polymerase chain reaction: a reliable and powerful diagnostic tool for pathologists. A molecular analysis of 221 mesenchymal tumors fixed in different fixatives. Hum Pathol. 2001;32:105-12

17. Udayakumar AM, Sundareshan TS, Goud TM, Devi MG, Biswas S, Appaji L, Arunakumari BS, Rajan KR, Prabha- 
karan PS. Cytogenetic characterization of Ewing tumors using fine needle aspiration samples. a 10-year experience and review of the literature. Cancer Genet Cytogenet 2000;127:42-8.

18. de Alava E, Lozano MD, Sola I, Panizo A, Idoate MA, Martinez-Isla C, Forteza J, Sierrasesumaga L, Pardo-Mindan FJ. Molecular features in a biphenotypic small cell sarcoma with neuroectodermal and muscle differentiation. Hum Pathol 1998;29:181-4.

19. de Alava E, Kawai A, Healey JH, et al. EWS-FLI1 fusion transcript structure is an independent determinant of prognosis in Ewing's sarcoma. J Clin Oncol. 1998;16:1248-55.

20. de Alava E, Gerald WL. Molecular biology of the Ewing's sarcoma/primitive neuroectodermal tumor family. J Clin Oncol 2000;18:204-13.

21. Gerald WL, Ladanyi M, de Alava E, Cuatrecasas M, Kushner BH, LaQuaglia MP, Rosai J. Clinical, pathologic, and molecular spectrum of tumors associated with $\mathrm{t}(11 ; 22)(\mathrm{p} 13 ; \mathrm{q} 12)$ : desmoplastic small round-cell tumor and its variants. J Clin Oncol. 1998;16:3028-36

22. Lee SB, Kolquist KA, Nichols K, Englert C, Maheswaran S, Ladanyi M, Gerald WL, Haber DA. The EWS-WT1 translocation product induces PDGFA in desmoplastic small round-cell tumour. Nat Genet. 1997;17:309-13.

23. Palmer RE, Lee SB, Wong JC, et al. Induction of BAIAP3 by the EWS-WT1 chimeric fusion implicates regulated exocytosis in tumorigenesis. Cancer Cell. 2002;2:497-505.

24. Zucman J, Delattre O, Desmaze C, Epstein AL, Stenman G, Speleman F, Fletcher CD, Aurias A, Thomas G. EWS and ATF-1 gene fusion induced by $\mathrm{t}(12 ; 22)$ translocation in malignant melanoma of soft parts. Nat Genet. 1993;4:341-5.

25. Hallor KH, Mertens F, Jin Y, Meis-Kindblom JM, Kindblom LG, Behrendtz M, Kalen A, Mandahl N, Panagopoulos I. Fusion of the EWSR1 and ATF1 genes without expression of the MITF-M transcript in angiomatoid fibrous histiocytoma. Genes Chromosomes Cancer 2005;44:97102

26. Antonescu CR, Tschernyavsky SJ, Woodruff JM, Jungbluth AA, Brennan MF, Ladanyi M. Molecular diagnosis of clear cell sarcoma: detection of EWS-ATF1 and MITF$M$ transcripts and histopathological and ultrastructural analysis of 12 cases. J Mol Diagn 2002;4:44-52.

27. Antonescu CR, Argani P, Erlandson RA, Healey JH, Ladanyi M, Huvos AG. Skeletal and extraskeletal myxoid chondrosarcoma: a comparative clinicopathologic, ultrastructural, and molecular study. Cancer 1998;83:1504-21.

28. Subramanian S, West RB, Marinelli RJ, Nielsen TO, Rubin BP, Goldblum JR, Patel RM, Zhu S, Montgomery K, Ng TL, Corless CL, Heinrich MC, van de Rijn M. The gene expression profile of extraskeletal myxoid chondrosarcoma. J Pathol 2005;206:433-44.

29. Aman P, Panagopoulos I, Lassen C, Fioretos T, Mencinger M, Toresson H, Hoglund M, Forster A, Rabbitts TH, Ron D, Mandahl N, Mitelman F. Expression patterns of the human sarcoma-associated genes FUS and EWS and the genomic structure of FUS. Genomics. 1996;37:1-8
30. Pérez-Mancera PA, Sánchez-García I. Understanding mesenchymal cancer: the liposarcoma-associated FUS-DDIT3 fusion gene as a model. Semin Cancer Biol 2005;15:20614.

31. Barr FG, Galili N, Holick J, Biegel JA, Rovera G, Emanuel BS. Rearrangement of the PAX3 paired box gene in the paediatric solid tumour alveolar rhabdomyosarcoma. Nat $\mathrm{Ge}-$ net. 1993;3:113-7.

32. Davis RJ, Barr FG. Fusion genes resulting from alternative chromosomal translocations are overexpressed by genespecific mechanisms in alveolar rhabdomyosarcoma. Proc Natl Acad Sci U S A. 1997;94:8047-51.

33. Sorensen PH, Lynch JC, Qualman SJ, et al. PAX3-FKHR and PAX7-FKHR gene fusions are prognostic indicators in alveolar rhabdomyosarcoma: a report from the children's oncology group. J Clin Oncol. 2002;20:2672-9.

34. Kawai A, Woodruff J, Healey JH, Brennan MF, Antonescu CR, Ladanyi M. SYT-SSX gene fusion as a determinant of morphology and prognosis in synovial sarcoma. N Engl J Med. 1998;338:153-60.

35. Ladanyi M, Antonescu CR, Leung DH, et al. Impact of SYT-SSX fusion type on the clinical behavior of synovial sarcoma: a multi-institutional retrospective study of 243 patients. Cancer Res. 2002;62:135-40.

36. Oliveira AM, Fletcher CD. Molecular prognostication for soft tissue sarcomas: are we ready yet? J Clin Oncol 2004;22:4031-4.

37. Knezevich SR, McFadden DE, Tao W, Lim JF, Sorensen PH. A novel ETV6-NTRK3 gene fusion in congenital fibrosarcoma. Nat Genet. 1998;18:184-7.

38. Tognon C, Knezevich SR, Huntsman D, Roskelley CD, Melnyk N, Mathers JA, Becker L, Carneiro F, MacPherson N, Horsman D, Poremba C, Sorensen PH. Expression of the ETV6-NTRK3 gene fusion as a primary event in human secretory breast carcinoma. Cancer Cell 2002;2:36776.

39. McArthur GA, Demetri GD, van Oosterom A, et al. Molecular and clinical analysis of locally advanced dermatofibrosarcoma protuberans treated with Imatinib: Imatinib Target Exploration Consortium Study B2225. J Clin Oncol 2005;23:866-73

40. Tuveson DA, Fletcher JA. Signal transduction pathways in sarcoma as targets for therapeutic intervention. Curr Opin Oncol. 2001;13:249-55.

41. Schleiermacher G, Peter M, Oberlin O, Philip T, Rubie H, Mechinaud F, Sommelet-Olive D, Landman-Parker J, Bours D, Michon J, Delattre O. Increased risk of systemic relapses associated with bone marrow micrometastasis and circulating tumor cells in localized Ewing tumor. J Clin Oncol. 2003;21:85-91

42. Kelly KM, Womer RB, Barr FG. Minimal disease detection in patients with alveolar rhabdomyosarcoma using a reverse transcriptase-polymerase chain reaction method. Cancer. 1996;78:1320-7

43. de Alava E. Transcripts, transcripts, everywhere. Adv Anat Pathol. 2001;8:264-72 


\section{E. de Álava}

44. Heinrich MC, Corless CL, Duensing A, et al. PDGFRA activating mutations in gastrointestinal stromal tumors. Science 2003;299:708-10.

45. Medeiros F, Corless CL, Duensing A, Hornick JL, Oliveira AM, Heinrich MC, Fletcher JA, Fletcher CD. KIT-negative gastrointestinal stromal tumors: proof of concept and therapeutic implications. Am J Surg Pathol 2004;28:889-94.

46. Kinoshita K, Hirota S, Isozaki K, Ohashi A, Nishida T, Kitamura Y, Shinomura Y, Matsuzawa Y. Absence of ckit gene mutations in gastrointestinal stromal tumours from neurofibromatosis type 1 patients. J Pathol. 2004; 202:80-5

47. Heinrich MC, Rubin BP, Longley BJ, Fletcher JA. Biology and genetic aspects of gastrointestinal stromal tumors: KIT activation and cytogenetic alterations. Hum Pathol. 2002;33:484-95.

48. Heinrich MC, Corless CL, Demetri GD, et al. Kinase mutations and Imatinib response in patients with metastatic gastrointestinal stromal tumor. J Clin Oncol. 2003;21:4342-9 (B).

49. Corless CL, Schroeder A, Griffith D, et al. PDGFRA Mutations In Gastrointestinal Stromal Tumors: Frequency, Spectrum and In Vitro Sensitivity To Imatinib. J Clin Oncol. 2005 (en prensa)

50. Singer S, Rubin BP, Lux ML, Chen CJ, Demetri GD, Fletcher CD, Fletcher JA Prognostic value of KIT mutation type, mitotic activity, and histologic subtype in gastrointestinal stromal tumors. J Clin Oncol 2002;20:3898-905.

51. Thomas DG, Giordano TJ, Sanders D, Biermann S, Sondak VK, Trent JC, Yu D, Pollock RE, Baker L. Expression of receptor tyrosine kinases epidermal growth factor receptor and HER-2/neu in synovial sarcoma. Cancer 2005; $103: 830-8$
52. Mohr S, Leikauf GD, Keith G, Rihn BH. Microarrays as cancer keys: an array of possibilities. J Clin Oncol 2002;20:3165-75.

53. Nielsen TO, West RB, Linn SC, Alter O, Knowling MA, O'Connell JX, Zhu S, Fero M, Sherlock G, Pollack JR, Brown PO, Botstein D, van de Rijn M. Molecular characterisation of soft tissue tumours: a gene expression study. Lancet 2002;359:1301-7.

54. Segal NH, Pavlidis P, Noble WS, Antonescu CR, Viale A Wesley UV, Busam K, Gallardo H, DeSantis D, Brennan MF, Cordon-Cardo C, Wolchok JD, Houghton AN. Classification of clear-cell sarcoma as a subtype of melanoma by genomic profiling. J Clin Oncol 2003;21:1775-81.

55. Nagayama S, Katagiri T, Tsunoda $T$, et al. Genome-wide analysis of gene expression in synovial sarcomas using a cDNA microarray. Cancer Res 2002;62:5859-66.

56. Lee YF, John M, Falconer A, et al. A gene expression signature associated with metastatic outcome in human leiomyosarcomas. Cancer Res 2004;64:7201-4

57. Wachtel M, Dettling M, Koscielniak E, Stegmaier S, Treuner J, Simon-Klingenstein K, Buhlmann P, Niggli FK, Schafer BW. Gene expression signatures identify rhabdomyosarcoma subtypes and detect a novel $\mathrm{t}(2 ; 2)(\mathrm{q} 35 ; \mathrm{p} 23)$ translocation fusing PAX3 to NCOA1. Cancer Res. 2004;64:5539-45.

58. Ladanyi M, Chan WC, Triche TJ, Gerald WL. Expression profiling of human tumors: the end of surgical pathology? J Mol Diagn 2001;3:92-7.

59. van de Rijn M, Rubin BP. Gene expression studies on soft tissue tumors. Am J Pathol 2002;161:1531-4.

60. O'Sullivan M, Budhraja V, Sadovsky Y, Pfeifer JD. Tumor heterogeneity affects the precision of microarray analysis. Diagn Mol Pathol 2005;14:65-71. 